\title{
A VOGAL EPENTÉTICA INICIAL EM ENCONTROS CONSONANTAIS /SC/ POR APRENDIZES DE INGLÊS COMO L2
}

\author{
THE VOWEL EPENTHESIS IN /SC / CLUSTERS BY BRAZILIAN \\ LEARNERS OF ENGLISH AS L2
}

\author{
Almir Anacleto de Araújo Gomes ${ }^{1}$ \\ Universidade Federal de Campina Grande (UFCG) \\ Rubens Marques de Lucena ${ }^{2}$ \\ Universidade Federal da Paraíba (UFPB)
}

\begin{abstract}
RESUMO
Este estudo descreve e analisa o processo variável de inserção da vogal [I] epentética em palavras iniciadas por encontros consonantais na língua inglesa por aprendizes brasileiros, do estado da Paraíba, de inglês como segunda língua (L2), tendo como base pesquisas realizadas a respeito desse fenômeno como: Escartín (2005) com aprendizes hispânicos de inglês como LDE e fenômenos semelhantes Cardoso (2004, 2008, 2009). O objetivo dessa pesquisa é, então, identificar a frequência da ocorrência de inserção da vogal de apoio na posição inicial das palavras em língua inglesa que se iniciam com um dos seguintes clusters /sp/, /st/, /sk/, /sl/, /sm/, e /sn/ por aprendizes brasileiros de inglês como L2. O corpus da pesquisa é constituído por 18 informantes paraibanos, aprendentes de inglês como LDE, pertencentes aos níveis de proficiência na LDE: básico, intermediário e avançado. Para a coleta dos dados de fala foi gravada a leitura de vinte e oito frases e um texto em inglês. $\mathrm{O}$ tratamento estatístico mostra, em ordem decrescente de significância, que as variáveis sonoridade do cluster, nível de proficiência, consciência fonológica do informante, contexto precedente ao cluster são as que se mostram mais relevantes à realização da epêntese vocálica inicial em cluster sC.
\end{abstract}

PALAVRAS-CHAVE: Epêntese Vocálica. Variação Linguística. Interlíngua. Aprendizagem de L2.

\begin{abstract}
This study aims to describe the variable process of inserting the epenthetic vowel [I] in words beginning with / $\mathrm{sC} /$ clusters at onset position in English by Brazilian learners of English as a second language (L2). This work is based on research conducted regarding this phenomenon such as: Escartín (2005) with Hispanic learners of English and Cardoso (2004, 2008, 2009). The research corpus is composed of data from 18 Brazilian learners of English as L2, distributed in basic, intermediate and advanced levels of proficiency. The independent variables are learner's level of proficiency and phonological awareness in the FL, sonority of the second element of the cluster, preceding phonological context and instrument type of data collection. The statistical analysis shows, in decreasing order of significance, that the sonority of the cluster, the learner's level of proficiency, the learner's phonological awareness, and the preceding context of the cluster are the most relevant variables to the realization of onset vowel epenthesis in $\mathrm{s} C$ clusters.

KEYWORDS: vowel epenthesis; language variation; interlanguage; foreign language learning.

\footnotetext{
1 Almir Anacleto de Araújo Gomes é professor da Unidade Acadêmica de Educação do Campo (UAEDUC) da Universidade Federal de Campina Grande (UFCG). É mestre e doutor em Linguística (Universidade Federal da Paraíba). É membro do Grupo de Pesquisa em Contato Linguístico da UFPB. E-mail: almir.ufcg@gmail.com.

2 Rubens Marques de Lucena é professor do Departamento de Letras Estrangeiras Modernas (DLEM) e do Programa de Pós-Graduação em Linguística (PROLING) da Universidade Federal da Paraíba (UFPB). É doutor em Linguística pela UFPB. É líder do Grupo de Pesquisa em Contato Linguístico da UFPB. E-mail: rubenslucena@yahoo.com.
} 


\section{INTRODUÇÃO}

A presente pesquisa tem por objetivo descrever e analisar o processo variável de inserção da vogal [I] epentética em palavras com certos encontros consonantais em posição inicial na língua inglesa na produção de aprendizes brasileiros de inglês como segunda língua (L2). Compreendemos a epêntese vocálica como um fenômeno de inserção de uma vogal de apoio para a reparação de um padrão fonotático não existente na língua (SILVA, 2011).

Assim, a epêntese vocálica é um "fenômeno que consiste em intercalar numa palavra ou grupo de palavras um fonema não-etimológico por motivos de eufonia, de comodidade articulatória, por analogia, etc" (DUBOIS, et al. 2006, p. 220).

Para tanto, procuramos identificar a frequência de ocorrência da inserção da epêntese vocálica inicial das palavras em língua inglesa que iniciam com um dos seguintes encontros consonantais: /sp-/ como em /spo:t/, /st-/ como em /stri:t/, /sk-/ como em /skri:n/, /sl-/ como em /slais/, /sm-/ como em /smərk/, e /sn-/ como em /snæk/ ${ }^{3}$ por aprendizes brasileiros de inglês como L2, levando em consideração o fato de que a primeira língua (L1) desses aprendizes, ou seja, o português brasileiro (PB), não apresenta a ocorrência de tais grupos consonantais na posição inicial, o que pode levar a uma possível dificuldade do indivíduo no aprendizado de uma língua que apresente esse tipo de ocorrência fonológica, como é o caso da língua inglesa.

\section{$1 \mathrm{O}$ fenômeno da epêntese vocálica inicial em encontros consonantais sC}

A sílaba do PB admite a seguinte estrutura máxima: C1C2VVC3C4, com pelo menos uma vogal no núcleo da sílaba (SILVA, 2011; 2012). Assim, podem ocorrer sílabas com uma ou duas consoantes pré-vocálicas. Quando se têm duas consoantes pré-vocálicas, a primeira consoante deve ser uma obstruinte, ou seja, uma consoante oclusiva ou fricativa pré-alveolar: /p, b, t, d, k, $\mathrm{g}, \mathrm{f}, \mathrm{v} /$; a segunda consoante obrigatoriamente de ser uma líquida, isto é, uma consoante lateral /1/ ou rótica /r/ (SILVA, 2011; 2012).

A variação de uso da epêntese está compreendida dentro do fenômeno denominado interlíngua ${ }^{4}$ (SELINKER, 1972), já que se está tratando de aprendizes de inglês como L2. Compreende-se que a aprendizagem de L2 não representa um fenômeno estático, e que fatores linguísticos, tais como contexto fonológico precedente e posterior e tamanho do encontro consonantal e extralinguísticos, tais como nível de proficiência e nível de consciência fonológica do falante, sexo e idade influenciam essa variação (GASS E SELINKER, 2008).

Brasileiros aprendizes de inglês como L2 podem apresentar certa dificuldade para adquirirem a pronúncia dos encontros consonantais $\mathrm{s} C$ da variedade padrão da língua inglesa, que pode ser atribuída à diferença na estrutura silábica entre as duas línguas. Com isso, esses aprendizes procuram uma forma de compensar essa estrutura não existente na sua L1 ao produzirem tais estruturas na língua alvo. Para que haja essa compensação, uma das estratégias utilizadas pelos aprendizes é acrescentar uma vogal [I] antes do encontro consonantal sC, promovendo uma ressilabação (SILVA, 2011). Assim, tem-se, por exemplo, 'smile' / smail/ $\rightarrow$ [IsmaIl].

Sendo a epêntese vocálica um fenômeno relacionado ao processo de silabação, "ela consequentemente também depende de direcionalidade" (COLLISCHONN, 1996 p. 150), ou seja, pode-se prever a posição da inserção da vogal com base na direção da silabação. Então, no

\footnotetext{
3 Apresentamos a transcrição fonética com base no inglês padrão britânico e no dicionário Cambridge Dictionary disponível em: https:// dictionary.cambridge.org/.

${ }^{4}$ A interlíngua é compreendida aqui como um fenômeno no qual o sistema linguístico do aprendiz de L2 adulto se diferencia tanto da sua língua nativa quanto da língua alvo, ao se expressar na L2. Ainda assim esse sistema linguístico apresenta elementos tanto da L1 quanto da L2 do aprendiz e tem como base a sua percepção de ambas as línguas.
} 
PB o alinhamento do molde silábico ocorre da direita para a esquerda admitindo-se assim a epêntese vocálica à esquerda (epêntese inicial \#CC $\rightarrow$ \#VCC). Assim, Collischonn (1996) aponta que a epêntese vocálica ocorre à esquerda quando a consoante perdida for a sibilante $/ \mathrm{s} /$.

Conforme pode-se perceber, uma série de fatores linguísticos, como contexto precedente, sonoridade da segunda consoante do encontro consonantal e fatores extralinguísticos, como proficiência, estilo ou nível de formalidade e consciência fonológica na L2, podem influenciar a ocorrência da vogal epentética, na produção dos aprendizes de L2, exatamente por sua tentativa de adequar os padrões fonotáticos da L2, os quais não foram ainda adquiridos adequadamente, com base nos padrões fonotáticos de sua L1.

A consciência fonológica é compreendida como uma sensibilidade do indivíduo aos sons da língua. Por conseguinte, a reflexão e a manipulação são elementos-chave dessa habilidade. A manipulação do sistema sonoro da língua compreende a habilidade de fracionar a língua oral em componentes menores, de apagar, substituir ou acrescentar sons a uma palavra, assim como ser capaz de perceber se determinada palavra apresenta uma sequência sonora bem formada, segundo os padrões fonotáticos da língua a qual pertence.

\section{A epêntese vocálica inicial em encontros consonantais $\mathrm{sC}$ nos estudos em Aquisição de L2 e Variacionistas}

Com o propósito de verificar se a relação de marcação em uma língua alvo influenciaria a dificuldade de aquisição da língua como L2, Carlisle (1988) desenvolveu a Hipótese de Marcação Intralingual (Intralingual Markedness Hypothesis - IMH) e investigou o efeito da marcação na aquisição de inglês como L2 por aprendizes falantes nativos de espanhol.

Para testar a IMH, duas condições foram estabelecidas: primeiro, que a estrutura da língua alvo deve ser diferente da estrutura na língua nativa do aprendiz e, segundo a estrutura na língua alvo deve estar em condição de marcação. Foi investigada a aquisição dos encontros consonantais $/ \mathrm{sl} /, / \mathrm{sm} / \mathrm{e} / \mathrm{sn} /$, em que todos atendem às condições de testagem de IMH.

Para a investigação, Carlisle (1988) selecionou 14 participantes adultos, falantes nativos de espanhol, da Colômbia, México e República Dominicana, sendo sete informantes do sexo masculino e sete informantes do sexo feminino. Para a coleta de dados, gravou-se a leitura de 435 sentenças, não relacionadas semanticamente entre si, pelos participantes, nas quais haviam 145 sentenças para cada encontro consonantal inicial (/sl/, /sm/ e /sn/).

Os resultados obtidos com essa investigação ajudaram a explicar, e não somente a apontar, um aspecto da interlíngua em L2, que trata da variabilidade. Os dados mostraram que a frequência média da epêntese vocálica inicial antes de / $\mathrm{sl} /$ foi significativamente inferior a $/ \mathrm{sm} / \mathrm{e}$ /sn/, apontando que estruturas menos marcadas são frequentemente menos modificadas que estruturas mais marcadas, isto é, apresentam uma maior facilidade de aquisição.

Um estudo de caso longitudinal foi conduzido por Abrahamsson (1999) com um falante adulto nativo de espanhol, da Bolívia, estudante de engenharia na Suécia, aprendendo sueco naquele país. O estudo foi conduzido de forma longitudinal com gravações de falas espontâneas do aprendiz a partir de agosto de 1990, 10 dias depois de o informante chegar a Suécia, até maio de 1991. O objetivo da investigação era verificar como se comportava o fenômeno da epêntese vocálica inicial na produção oral do informante ao longo do tempo, conforme a sua proficiência na L2 ia se desenvolvendo.

A investigação replicou os estudos de Carlisle (1988, 1991a, 1991b, 1992, 1994, 1997, 1998) que tinham como foco o fenômeno da epêntese vocálica inicial sob as condições contexto precedente, extensão do encontro consonantal, e sonoridade em condições de fala elicitada. Abrahamsson (1999), então, investigou, além desses pontos, o aspecto de desenvolvimento da produção dos encontros consonantais de forma longitudinal, levando em conta o nível de 
proficiência do aprendiz, além de outras variáveis como contexto precedente, tamanho e sonoridade do encontro consonantal e a relação dessas duas últimas variáveis.

Os resultados obtidos confirmam os estudos anteriores a respeito da produção dos encontros consonantais $\mathrm{sC}$, em que o contexto precedente influencia na produção da epêntese vocálica, sendo o uso mais frequente quando o contexto precedente trata de um som consonantal. A extensão do encontro consonantal também favorece o aparecimento da epêntese, ou seja, encontro consonantal com três segmentos após /s/ é o contexto mais favorável para o aparecimento da vogal epentética do que apenas com dois membros (CARLISLE, 1988). Por ser um estudo longitudinal, percebeu-se que o efeito de diminuição da frequência de produção da epêntese vocálica inicial não decresce de forma retilínea a partir do início da aprendizagem da L2, porque há variações durante o processo.

Levando em conta estudos de fonologia de L2, as hipóteses da Análise Contrastiva, bem como a Hipótese da Marcação Diferencial $(\mathrm{MDH})$ e a Hipótese da Conformidade Estrutural da Interlíngua (ISCH), Chen (2003) procurou investigar o desenvolvimento fonológico da interlíngua de falantes nativos de chineses aprendizes de inglês como L2. Para tanto, verificou-se como esses chineses aprendizes de inglês como L2 produziam encontros consonantais iniciais triconsonantais e bi-consonantais. Para tal, considerou-se, por exemplo, o fato de a língua inglesa permitir encontros consonantais iniciais de até três elementos $(C)(C)(C) V(C)(C)(C)$, enquanto que o chinês só admite o máximo de dois elementos, sendo o segundo deles um glide (CGVX: $\mathrm{C}=$ consoante inicial, $\mathrm{G}=$ glide, $\mathrm{V}=$ núcleo, $\mathrm{X}=$ coda), que pode ser nasal ou glide).

Para a realização da pesquisa, nove informantes participaram do experimento, sendo três informantes do sexo feminino e seis informantes do sexo masculino. Dos participantes, sete estudavam inglês há pelo menos 4 anos e estavam em uma faixa etária média de 17 anos de idade. Os outros dois participantes, um de 23 anos de idade e outro de 55, tiveram instrução de língua inglesa apenas na escola. Todos os participantes eram falantes nativos de chinês e a maioria deles tinham pouca proficiência em tailandês. A coleta de dados foi realizada em duas etapas: a primeira etapa consistiu de 10 sentenças contendo nove palavras com encontro inicial triconsonantal e 11 palavras com encontro consonantal inicial bi-consonantal. A segunda etapa consistiu de uma lista de 15 palavras com encontro inicial tri-consonantal e 30 palavras com encontro inicial bi-consonantal. As frases e palavras lidas pelos informantes foram gravadas e depois transcritas foneticamente por dois falantes nativos de inglês, com treinamento em linguística.

Os resultados mostraram que os chineses modificaram com mais frequência encontros inicias tri-consonantais $(23,7 \%)$, os quais segundo a $\mathrm{MDH}$ são mais marcados, do que os biconsonantais $(9,3 \%)$, levando, então, a entender que os aprendizes chineses de inglês como L2 adquirem os encontros bi-consonantais antes dos tri-consonantais. Essa investigação, no entanto, não considerou variáveis como idade dos participantes, sexo ou nível de proficiência na L2.

Tendo como referência os estudos de Carlisle (1991, 1992, 1997) e Rebello (1997), cujos resultados se contradizem em alguns pontos, Rauber (2002) e Rauber e Baptista (2004) desenvolveram um estudo com o objetivo de investigar a dificuldade na produção de encontros consonantais $\mathrm{sC}$ iniciais em inglês como L2, por falantes nativos de português do Brasil e por falantes nativos de espanhol da Argentina. Para tanto, Rauber e Baptista (2004) descrevem brevemente a estrutura silábica de cada língua e apresentam estudos que mostram as principais estratégias usadas pelos aprendizes para superar essas dificuldades na produção de encontros consonantais $\mathrm{sC}$ iniciais.

Participaram da investigação nove falantes nativos de espanhol da Argentina, matriculados no primeiro e segundo anos de curso de Letras e dez falantes nativos de português do Brasil cursando segundo e terceiro anos do curso de Letras. Os informantes foram solicitados a ler 180 sentenças de temas diversificados. As sentenças foram distribuídas de forma a contemplar de forma igualitária palavras com um dos encontros consonantais $\mathrm{s} C$ iniciais estudados $(/ \mathrm{sp} /, / \mathrm{st} /$, 
/sk/, /sw/, /sm/, /sn/, /sl/, /spr/, /str/, /skr/, /spl/ e /skw/, bem como tendo o contexto precedente controlado, entre três fatores: vogal, consoante ou silêncio. A parte de cada sentença considerada importante para a pesquisa foi transcrita, com foco para a presença ou ausência da epêntese vocálica inicial, a realização fonética do contexto precedente e a representação fonética do encontro consonantal inicial. As variáveis possíveis inibidoras da pronúncia da língua alvo foram analisadas estatisticamente através do teste de significância qui-quadrado, que permite testar a significância relativa das variáveis.

Assim, com base nos estudos de Carlisle (1991, 1992, 1997) e Rebello (1997), Rauber \& Baptista (2004) formularam três hipóteses: 1) falantes nativos de espanhol tenderiam a modificar encontros consonantais mais longos, enquanto falantes nativos de português tenderiam a modificar grupos menores mais frequentemente; 2) falantes nativos de espanhol tenderiam a modificar estruturas mais marcadas, enquanto falantes nativos de português tenderiam a modificar estruturas menos marcadas; e 3) falantes de espanhol tenderiam a produzir mais epênteses após consoantes, seguidas de vogais, e em seguida pelo silêncio, enquanto falantes de português usariam mais a epêntese com mais frequência após silêncio, seguido de consoantes e depois por vogais.

Os resultados demonstraram que tanto os falantes nativos de espanhol quanto os de PB, aprendizes de inglês como L2 utilizaram mais a estratégia de epêntese vocálica antes de encontros tri-consonantais do que antes de encontros bi-consonantais. Com isso, confirmam-se as previsões baseadas na $\mathrm{MDH}$, corroborando a hipótese para os falantes nativos de espanhol, mas não para os falantes nativos de português.

Entretanto, em relação aos falantes nativos de português, os resultados foram inconcludentes. Quanto à terceira suposição, os resultados confirmaram para os falantes nativos de espanhol que a frequência de inserção da epêntese vocálica é maior após contexto de consoantes, seguido de vogais, e por fim silêncio.

Em relação aos falantes nativos de português, esse estudo confirmou parcialmente os resultados de Rebello (1997), já que os resultados mostraram que estes introduziram a vogal epentética mais frequentemente após contexto de vogal, seguido de consoante e por fim de silêncio.

Adiante, Escartín (2005) investiga a produção da epêntese vocálica [e] na produção de aprendizes de inglês como L2 por falantes nativos de espanhol no ambiente de sala de aula. A pesquisa leva em conta fatores linguísticos, a exemplo de contexto fonológico precedente, perfil sonoro dos componentes dos encontros consonantais, e fatores extralinguísticos, como nível de formalidade e proficiência dos aprendizes como possíveis favorecedores da produção da vogal epentética.

Os dados obtidos por Escartín (2005) foram tratados através do GoldVarb 2001, um programa utilizado para tratamento de dados estatísticos, e analisados segundo a Teoria da Otimidade, combinando ferramentas metodológicas de três disciplinas diferentes: a Sociolinguística, a Aquisição de L2 e a Fonologia.

Quanto aos fatores linguísticos, os resultados do estudo mencionado anteriormente demonstram que contexto precedente se comporta de maneira semelhante, quanto à produção da epêntese vocálica, seja uma pausa ou uma consoante precedente; já o contexto de vogal precedente facilita a produção da epêntese por aprendizes hispânicos de inglês como L2. Além disso, a produção de encontros consonantais $\mathrm{s} C$ formados por $\mathrm{s}+$ consoante obstruinte são mais difíceis de ser adquiridos (CARLISLE, 1988). Em relação aos fatores extralinguísticos, o estudo corroborou outros estudos em Aquisição de L2, demonstrando que, conforme o nível de proficiência do aprendiz se eleva, a frequência de produção da vogal epentética decresce.

Para Bettoni-Techio \& Koerich (2007), embora a produção de palavras com encontros consonantais $\mathrm{s} C$ iniciais em inglês como L2 por aprendizes brasileiros seja problemático, a mera 
tomada de consciência desse fato pelos aprendizes não é suficiente para uma produção semelhante à língua alvo. Assim, desenvolveram uma investigação nesse âmbito.

Participaram da pesquisa dois adultos brasileiros aprendizes de inglês como L2 de nível intermediário de proficiência na L2. Foram aplicados pré-testes de percepção e de produção, um treinamento de percepção, dividido em seis sessões, e pós-testes de percepção e de produção. Além desses testes, foram realizados, cinco meses após o treinamento, os testes de retenção. Tanto os pós-testes como os testes de retenção foram idênticos aos pré-testes. $O$ foco da investigação foi os encontros consonantais /sl/, /sm/, /sn/, /sk/, /sp/, /skr/ e /spr/.

Os objetivos da investigação eram identificar os efeitos de treinamento perceptual, que trata de uma abordagem de ensino de pronúncia assistida por computador, na pronúncia de palavras iniciadas por encontros consonantais $\mathrm{sC}$ em inglês como L2 por aprendizes brasileiros; verificar se havia uma melhor percepção e produção de palavras com encontros consonantais $\mathrm{s} C$ iniciais, tanto em relação à epêntese vocálica inicial como em relação à troca de sonoridade nos encontros consonantais e maior retenção cinco meses após o teste; se a melhora seria transferida para um falante desconhecido para encontros consonantais não treinados anteriormente (BET'TONITECHIO E KOERICH, 2007).

Os resultados obtidos por Bettoni-Techio e Koerich (2007) confirmaram sua primeira hipótese de se obter resultados diferentes no pré-teste e no pós-teste, evidenciando que o treinamento afetou a percepção do participante melhorando a sua produção. Assim, também foi confirmada a hipótese de que essa melhoria na produção perdurou durante os cinco meses seguintes na realização do teste de retenção, demonstrando que o monitoramento leva a uma melhor produção em L2.

Cornelian Jr. (2007), percebendo que muitos estudantes brasileiros de L2 atingem um nível de proficiência comparável ao nativo em competência gramatical e lexical, mas que não têm a mesma competência em relação à pronúncia, decidiu investigar quais fatores podem inibir o desenvolvimento da proficiência na pronúncia em L2.

$\mathrm{O}$ foco da pesquisa foi a aquisição da pronúncia do /s/ inicial antes de encontros consonantais $\mathrm{sC}$ por aprendizes brasileiros de inglês como L2, levando em consideração que o contexto precedente ao encontro consonantal $\mathrm{sC}$ atua de forma especial na hierarquia de dificuldade de aquisição (CARLISLE, 1988) da pronúncia dos encontros consonantais.

Para atingir os objetivos propostos, Cornelian Jr. (2007) procurou responder algumas questões relacionadas à frequência de uso da epêntese vocálica em diferentes contextos e estruturas fonológicas por aprendizes brasileiros de inglês como L2.

A primeira pergunta está relacionada ao comprimento do encontro consonantal como fator influente na produção da epêntese vocálica inicial. No entanto, os dados não permitiram estabelecer uma posição firme se os encontros consonantais sCC eram mais propícios à inserção da vogal epentética do que os encontros consonantais $\mathrm{sC}$.

A segunda questão investigada diz respeito à relação da sonoridade do encontro consonantal com a frequência de produção da variante com epêntese vocálica. Os resultados mostraram que os encontros consonantais $\mathrm{sC}$ com soantes são maiores facilitadores de ocorrência do fenômeno observado do que os encontros consonantais sC com oclusivas. Cornelian Jr. (2007) investigou ainda se a tendência dos brasileiros de pronunciar o som /s/ vozeado antes de encontros consonantais vozeados influenciaria a ocorrência da epêntese vocálica inicial, o que se evidenciou de fato como um fator influente a partir dos dados analisados.

Por fim, foi investigado se o contexto precedente vocálico ou consonantal seria o mais facilitador para a ocorrência da epêntese vocálica inicial em encontros consonantais sC. Corroborando estudos anteriores (REBELLO, 1997ab; RAUBER, 2002), o contexto vocálico precedente propiciou uma maior frequência da epêntese vocálica por aprendizes brasileiros de inglês como L2. Além disso, Cornelian Jr. (2007) propõe uma hierarquia no ensino dos encontros 
consonantais, indo do menos complicado para a produção oral para o mais difícil no contexto de ensino brasileiro.

Para que fosse possível traçar um paralelo entre a percepção e produção de encontros consonantais $\mathrm{sC}$ na interlíngua de aprendizes brasileiros de inglês como L2, Cardoso, John e French (2009) investigaram o desenvolvimento perceptual de três encontros consonantais homorgânicos, ou seja, que apresentam o mesmo ponto de articulação, /sl/, /sn/ e /st/, nesse caso coronais, com o objetivo de responder às seguintes questões: Como a percepção do encontro consonantal $\mathrm{sC}$ se desenvolve durante a aprendizagem do aprendiz brasileiro de inglês como L2? Que fatores contribuem para a aquisição desses encontros consonantais iniciais? Como se dá o desenvolvimento da aquisição perceptual desses encontros consonantais comparado com pesquisas cujo foco era a produção oral?

Para responder as questões propostas, dois estudos foram realizados. O primeiro estudo contou com 10 participantes adultos brasileiros que nunca haviam sido expostos à língua inglesa de forma oral. Os participantes sentavam-se na frente de um computador, ouviam uma sequência de palavras criadas por um programa de computador, segundo determinadas regras, e tinham de decidir com qual dos três encontros consonantais iniciava-se cada palavra. A partir desse estudo, observou-se que 95\% dos participantes responderam ao teste com acuidade, mostrando que falantes nativos do PB não têm problemas em identificar ou distinguir entre os encontros consonantais investigados.

O segundo estudo contou com 24 participantes, sendo oito participantes de cada nível de proficiência diferente, a saber, sem conhecimento nenhum de inglês, intermediário e avançado. Similar ao teste elaborado para o primeiro estudo, os participantes deveriam escolher no computador, ao ouvir as palavras criadas para a investigação, entre três opções: se a palavra começava com vogal, com /s/ ou um sinal de interrogação, caso o participante ficasse com dúvida.

Os dados foram tratados com o programa estatístico GoldVarb X (SANKOFF, TAGLIAMONTE E SMITH, 2005). Para tanto, os dados foram categorizados quanto à acuidade da resposta, (correta ou incorreta identificação), quanto à proficiência dos participantes (sem conhecimento de inglês, intermediário ou avançado), quanto a extensão das palavras do teste (1 sílaba ou 2 ou mais sílabas), quanto à sonoridade do encontro consonantal sC (/st/, /sn/ ou $/ \mathrm{sl} /$ ) e quanto aos participantes (informante 1 ao 24). Os resultados obtidos mostraram que quanto mais proficiente, maior a habilidade do participante em identificar corretamente os encontros consonantais investigados.

Cardoso $(2007,2008)$ investigou o efeito da marcação e da frequência de input na variação de aquisição de encontro consonantal $\mathrm{s} C$ inicial na fala de aprendizes brasileiros de inglês como L2 em ambiente de sala de aula, já que há duas correntes que tentam explicar o fenômeno analisado: a primeira, baseada na MDH de Eckman (1977 apud CARDOSO, 2007, 2008), compreende que, quanto maior a diferença entre a estrutura na língua alvo em relação à L1 do aprendiz, ou seja, quanto mais marcada for a estrutura alvo, mais dificuldade terá o aprendiz de adquiri-la.

Por outro lado, com o desenvolvimento das pesquisas baseadas na frequência de input recebido pelo aprendiz, passou-se a propor que, quanto maior a frequência de uso das expressões alvo, maior será a facilidade de aquisição de tais expressões.

O estudo teve como foco os encontros consonantais /st/, /sn/ e /sl/, por apresentarem a característica comum do ponto de articulação em sua produção, ou seja, são sons coronais. Para efeitos de investigação, foi considerada como hipótese do efeito de marcação o encontro consonantal /sl/ como mais fácil de articular ou adquirido anteriormente, seguido de /sn/ e por fim o /st/. Em contraponto, foi considerada a hipótese de frequência, que aponta /st/ como o encontro consonantal mais frequentemente usado, consequentemente, mais fácil de ser aprendido, seguido de /sl/ e por último /sn/. 
Para a coleta de dados foram gravadas 30 horas de áudio de um professor de inglês como L2 para definição da frequência de input de encontros consonantais na sala de aula a que os aprendizes foram submetidos. Em seguida, foram investigados dez aprendizes brasileiros de inglês como L2 de dois níveis de proficiência diferentes: pré-intermediário e avançado. A pesquisa seguiu padrões sociolinguísticos de coleta e tratamento de dados e chegou a resultados que indicaram que os aprendizes têm mais facilidade de produzir os encontros consonantais $\mathrm{s} C$ da forma alvo quando mais proficientes na língua estrangeira, principalmente quando se trata dos encontros consonantais / sl/ ou / sn/.

Boudaoud e Cardoso (2009) procuraram investigar a variação da produção de encontros consonantais $\mathrm{sC}$ na posição inicial por nativos de língua persa aprendizes de inglês como L2. O estudo teve como foco a produção dos encontros consonantais /st/, /sn/ e /sl/ por serem homorgânicos, isto é, tratar-se de três sons coronais, como mencionado anteriormente, apresentando assim, o mesmo ponto de articulação na produção em L2. Assim como no estudo de Escartín (2005), essa investigação utilizou ferramenta da Sociolinguística Variacionista levando em consideração tanto fatores linguísticos como contexto precedente (som consonantal, vocálico ou pausa), marcação da sonoridade do encontro consonantal, bem como fatores extralinguísticos, como proficiência dos informantes da pesquisa (iniciantes, intermediários e avançados) e nível de formalidade da coleta de dados (formal ou informal), como possíveis facilitadores da produção da epêntese vocálica na produção dos encontros consonantais sC. Além disso, os dados de 30 adultos falantes nativos de língua persa foram analisados com base nos escopos da Fonologia e da Aquisição de Segunda Língua (Second Language Acquisition).

Como resultado do estudo realizado, ao contrário do trabalho de Escartín (2005), Boudaoud e Cardoso (2009) detectaram que a inserção da epêntese vocálica é mais propícia de ocorrer com contexto precedente de som consonantal ou pausa do que com som vocálico. Compreende-se, assim, que o contexto vocálico precedente é facilitador da aprendizagem da pronúncia alvo de inglês como L2.

Em relação aos fatores de extralinguísticos, foi verificado que o nível de proficiência e o nível de formalidade influenciaram na produção da epêntese vocálica, ou seja, quanto menos proficiente era o aprendiz, ou quanto menos informal era a situação de produção, mais ocorria a epêntese vocálica com os encontros consonantais sC analisados. Verificou-se também que, quanto maior o nível de proficiência e de formalidade, menor o aparecimento da epêntese citada.

Com relação à produção de encontros consonantais sC iniciais, Carlisle e Espinosa (2010) desenvolveram um estudo longitudinal com alguns objetivos, como o de verificar se a influência da marcação permaneceria tão forte no primeiro momento da pesquisa quanto no segundo momento, e calcular se a frequência de produção segundo a norma culta na língua alvo aumentava enquanto o tempo passava. Além disso, Carlisle e Espinosa (2010) tiveram como objetivo verificar se os mesmos participantes que produziam encontros consonantais $\mathrm{sC}$ iniciais conforme a língua alvo no primeiro momento seriam os mesmos a produzirem no segundo momento da pesquisa, e, por fim, analisar as possíveis causas da mudança na produção de encontros consonantais $/ \mathrm{sC} /$ em posição inicial, através do cruzamento de variáveis que possam interferir na produção de L2.

$\mathrm{Na}$ primeira fase da pesquisa, 17 informantes participaram da coleta de dados, mas somente doze deles estavam na segunda etapa. Todos os participantes eram adultos falantes nativos de espanhol, matriculados em curso de inglês como L2, em nível intermediário. Para a coleta de dados, foram usadas 375 sentenças, 125 para cada encontro consonantal investigado (/sl/, / sn/ e /st/), tendo o contexto precedente controlado, além de um questionário, no qual os participantes davam informações sobre como eles usavam a língua inglesa cotidianamente. As sentenças foram lidas e gravadas duas vezes com diferença exata de um ano da primeira para a segunda gravação. Após a coleta, os dados foram transcritos pelos dois pesquisadores envolvidos e, em seguida, 
foram calculados quanto à interferência de variáveis a partir do cálculo estatístico de ANOVA (Análise de Variância).

Os resultados mostraram que a influência de marcação permaneceu tão forte na segunda etapa da pesquisa quanto na primeira, ou seja, quanto menos marcado é o encontro consonantal, maior a frequência de uma produção esperada, correspondendo ao primeiro objetivo da investigação. Quanto ao segundo objetivo da pesquisa, observou-se que a frequência de produção segundo a língua alvo aumentou com o tempo, ou seja, da primeira para a segunda etapa, os resultados não foram significantes, com apenas $4 \%$ de diferença de uma etapa para a outra. Em relação ao terceiro objetivo, dois dos participantes que atingiram a produção esperada na primeira etapa não atingiram na segunda.

Mildner e Tomić (2011) investigaram o quão bem-sucedido seria a aquisição de encontros consonantais $\mathrm{sC}$ iniciais por crianças croatas entre dois e quatro anos de idade. O objetivo do estudo, então, foi analisar a aquisição de nove encontros consonantais $\mathrm{sC}$ em posição inicial, /sp/, /st/, /sk/, /sm/, /sn/, /sl/, /sr/, /sv/ e /sj/ por crianças croatas. A coleta de dados se deu com uma gravação de uma tarefa, na qual os 30 participantes, em fase pré-escolar, com idade média de 38 meses (aproximadamente 3 anos), dariam nomes às figuras visualizadas enquanto eram gravados para posterior análise pelos pesquisadores.

Os dados foram analisados quanto à porcentagem de erros e acertos em relação à pronúncia dos encontros consonantais $\mathrm{sC}$ iniciais mencionados, na norma culta da língua croata. Os encontros consonantais que obtiveram uma porcentagem mais alta de acertos foram aqueles formados por /s/ + consonante nasal (71\% de produção correta), seguido de /s/ + consoante obstruinte $(66 \%$ de produção correta), com a redução do segundo elemento do encontro consonantal, sendo o erro mais frequente. Com relação aos erros com encontros consonantais do tipo /s/ + consoante aproximadamente ( $57 \%$ de respostas corretas), sendo mais frequente o apagamento do primeiro elemento. E por fim, com apenas $24 \%$ de acertos, o encontro consonantal /sr/ teve com mais frequência a substituição do /r/ por outro som.

Conforme podemos observar nos resultados dos trabalhos apresentados, diversas variáveis atuam na realização da epêntese vocálica inicial na interlíngua de aprendizes de L2, levando-nos a buscar uma compreensão desse fenômeno a partir das teorias de aquisição de L2 e da sociolinguística variacionista.

A sociolinguística variacionista propõe explicação do caos linguístico, através da sistematização da variação, que é entendida como duas ou mais maneiras de passar a mesma informação (TARALLO, 2007). Cada uma dessas formas alternativas, que formam o fenômeno variável, é uma variante.

Assim também afirma Calvet (2002, p. 103) que há uma variação linguística "quando dois significantes têm o mesmo significado e quando as diferenças que eles representam têm uma função outra, estilística ou social" dentro de uma comunidade de fala. Ao conceber que o aprendiz brasileiro de inglês como L2 enuncia a palavra "space" como /speIs/ ou como [IspeIs], entendem-se essas realizações como uma variação linguística, duas alternativas produzidas por tais aprendizes.

Dessa forma, o objeto de análise da sociolinguística é a língua falada, isto é, a língua usada para a comunicação do dia a dia em situações autênticas de uso. Assim, a Sociolinguística Variacionista procura o entendimento do sistema subjacente às variantes linguísticas, com foco especial para as variantes estigmatizadas (BAYLEY E LUCAS, 2007).

Paralelamente e convergindo para os estudos variacionistas, surgem os estudos em aquisição de L2, que procuram compreender como se dá o processo de aquisição de L2. De acordo com Bayley (2007), pode-se considerar que essas duas áreas de investigação surgem com um interesse em comum, que é compreender o sistema subjacente da variedade linguística, ou seja, a sociolinguística procura entender o sistema subjacente à variação linguística, e os estudos em Aquisição de Segunda Língua, o sistema subjacente da interlíngua do aprendiz de L2. 
Dentro dos estudos de aprendizagem de L2 surgem as investigações a respeito da interlíngua, definido por Selinker (1972) como um sistema aproximado contendo regras da língua alvo e da L1 do aprendiz, mas que não pode ser explicado apenas por essas regras. Dessa forma, busca-se na Teoria da Variação laboviana explicar a variação na interlíngua de aprendizes de L2 também.

Por outro lado, um dos equívocos das pesquisas variacionistas com foco na língua do aprendiz de L2, segundo Bayley (2005), é explicar a variação encontrada na língua de um aprendiz com apenas um fator de influência, já que as pesquisas sob abordagem variacionista partem do princípio de que "A variação da interlíngua, como a variação em qualquer língua, é susceptível à influência não só de uma, mas de múltiplas influências contextuais "(tradução nossa) (BAYLEY, 2005 p.135), isto é, o pesquisador não deve buscar qual é o único fator responsável pela variação produzida pelo aprendiz de L2, mas qual é o peso relativo dos diferentes fatores responsáveis por essa variação (BAYLEY, 2005).

\section{Metodologia}

O corpus deste estudo compõe-se de dados de 18 brasileiros, que nasceram ou moram por mais de cinco anos nas cidades de Campina Grande ou João Pessoa, no estado da Paraíba. Os informantes apresentavam, portanto, características do falar paraibano. Outro critério para a seleção dos informantes foi o fato de que eles deveriam ser aprendizes de inglês como L2. Eles foram divididos em três níveis de proficiência: básico, intermediário e avançado. A estratificação dos informantes se deu a partir da aplicação do teste de proficiência Oxford Placement Test (ALLAN, 2004).

Neste estudo investigamos o papel das variáveis independentes proficiência na língua; tipo de instrumento; contexto fonológico precedente (figura 02); sonoridade do encontro consonantal; e consciência fonológica no favorecimento ou inibição da vogal epentética (variável dependente), no contexto já mencionado.

\begin{tabular}{|c|c|c|}
\hline Cluster & Consoante precedente & Exemplo \\
\hline \multirow{3}{*}{ /st/ } & Labial & ...cab stopped \\
\hline & Coronal & ...and Steve \\
\hline & Dorsal & ...big stadium \\
\hline \multirow{3}{*}{$/ \mathrm{sm} /$} & Labial & ...room smells \\
\hline & Coronal & ... and smile \\
\hline & Dorsal & ...big smile \\
\hline \multirow{3}{*}{ /sp/ } & Labial & ...of spiders \\
\hline & Coronal & ...In spite \\
\hline & Dorsal & ...doing sports \\
\hline \multirow{3}{*}{ /s1/ } & Labial & \\
\hline & Coronal & ...soon slapped \\
\hline & Dorsal & ...like slithering \\
\hline \multirow{3}{*}{ /sn/ } & Labial & ...five snakes \\
\hline & Coronal & ...terrible snow \\
\hline & Dorsal & ... big snowball \\
\hline \multirow{3}{*}{ /sk/ } & Labial & ...five skirts \\
\hline & Coronal & ...fun sketch \\
\hline & Dorsal & ...pink skirt \\
\hline
\end{tabular}

Figura 02: Encontro consonantal inicial com contexto fonológico consonantal precedente. 
Em relação à consciência fonológica, os informantes desta pesquisa foram estratificados (figura 03) em: aprendizes com consciência fonológica são os informantes que cursam ou cursaram Letras com habilitação em língua inglesa e já tenham cursado alguma disciplina de Fonética e Fonologia; aprendizes sem consciência fonológica são aqueles que não tiveram formação a respeito de fonética ou fonologia de língua inglesa.

\begin{tabular}{|c|c|c|c|c|c|}
\hline CÉLULA 01 & CÉLULA 02 & CÉLULA 03 & CÉLULA 04 & CÉLULA 05 & CÉLULA 06 \\
\hline Nível Básico & $\begin{array}{c}\text { Nível } \\
\text { Intermediário }\end{array}$ & $\begin{array}{c}\text { Nível } \\
\text { Avançado }\end{array}$ & Nível Básico & $\begin{array}{c}\text { Nível } \\
\text { Intermediário }\end{array}$ & $\begin{array}{c}\text { Nível } \\
\text { Avançado }\end{array}$ \\
\hline $\begin{array}{c}\text { Com } \\
\text { Consciência } \\
\text { Fonológica }\end{array}$ & $\begin{array}{c}\text { Com } \\
\text { Consciência } \\
\text { Fonológica }\end{array}$ & $\begin{array}{c}\text { Com } \\
\text { Consciência } \\
\text { Fonológica }\end{array}$ & $\begin{array}{c}\text { Sem } \\
\text { Consciência } \\
\text { Fonológica }\end{array}$ & $\begin{array}{c}\text { Sem } \\
\text { Consciência } \\
\text { Fonológica }\end{array}$ & $\begin{array}{c}\text { Sem } \\
\text { Consciência } \\
\text { Fonológica }\end{array}$ \\
\hline
\end{tabular}

Figura 03: Distribuição das células para estratificação dos informantes

Diante disso, assume-se que os indivíduos que apresentam consciência fonológica, ou seja, indivíduos que cursaram alguma disciplina como fonética ou fonologia, apresentam um menor índice de uso da epêntese vocálica inicial antes de clusters $\mathrm{sC}$.

A coleta de dados é muito importante para a Sociolinguística Variacionista, pois a maneira como é realizada pode influenciar o resultado do estudo, enviesando-o. Apesar de a entrevista de experiência pessoal ser o principal método de coleta de dados neste tipo de pesquisa, Labov (1972) apresenta outros meios que também podem ser utilizados para coleta de dados, entre eles, a leitura de listas de palavras e de texto (PEREYRON, 2008), os quais são usados nessa pesquisa.

Este estudo conta com um total de dois instrumentos, de forma a contemplar dois estilos: um estilo de leitura (reading style) e um estilo informal, baseado em um teste de julgamento gramatical. O estilo de leitura referindo-se, como o termo sugere, à leitura de um texto construído, de forma que o fenômeno observado ocorresse segundo cada contexto fonológico investigado.

Quanto ao estilo informal, considera-se a atividade de julgamento gramatical das frases, esperando-se que os informantes estariam preocupados com a estrutura gramatical da frase ao invés da estrutura fonológica, levando-os a produzir tais frases mais naturalmente. $O$ teste consistiu de 28 pares de sentenças semelhantes com uma pequena mudança gramatical ou de vocabulário de uma sentença para outra dentro do par. Solicitou-se do participante a leitura, em vOz alta, apenas da sentença que ele julgasse gramaticalmente mais aceitável.

As sentenças, entretanto, eram formadas com palavras contendo o fenômeno da epêntese vocálica inicial em cluster $\mathrm{sC}$ tendo controlado contexto precedente e sonoridade do cluster, conforme o exemplo, a seguir:

a) The cab stopped to pick up three Spanish guys.

b) The cab stopped for pick up three Spanish guys.

Figura 01: Modelo do teste de julgamento gramatical 
Esperava-se que a presença da epêntese vocálica inicial em encontros consonantais sC ocorreria mais no estilo informal, em que o informante não se monitora tanto em relação à pronúncia.

Apresenta-se, a seguir, dados e resultados da pesquisa realizada.

\section{Resultados}

Ao todo foram geradas 1440 ocorrências, as quais foram submetidas à análise do GoldVarb X (SANKOFF, TAGLIAMONTE E SMITH, 2005), sendo 685 ocorrências da tarefa de julgamento gramatical, considerada aqui como tendo menor nível de formalidade e 755 ocorrências da leitura do texto, considerado com maior nível de formalidade nesta pesquisa.

Os dados revelaram que, de um total de 1440 ocorrências, 852 foram de epêntese vocálica, o que equivale a $59,2 \%$ de ocorrência do fenômeno observado e 588 ocorrências de não inserção da vogal epentética, equivalendo a 40,8\% do total de ocorrências (Gráfico 01). Uma vez que os informantes desta pesquisa aprendem inglês como L2 em situação formal de aprendizagem, isso remete ao fato de eles estarem aprendendo a variedade formal da língua inglesa.

Como se pode observar, há um alto índice de ocorrência da epêntese vocálica produzida por aprendizes brasileiros de inglês como L2, o que pode levar a refletir sobre a importância da instrução formal na aprendizagem da língua estrangeira padrão, que parece ser insuficiente para desenvolver tanto a consciência fonológica do aprendiz de L2 como mesmo a aquisição fonológica da língua alvo.

A variável da sonoridade do encontro consonantal foi selecionada pelo programa como a mais relevante para a inserção da vogal epentética, nesta pesquisa. Os resultados mostraram que a aplicação da epêntese vocálica foi mais forte nos encontros consonantais / sn/ com peso relativo $0.70, / \mathrm{sl} / \mathrm{com}$ peso relativo $0.58 \mathrm{e} / \mathrm{sm} / \mathrm{com}$ peso relativo 0.57 .

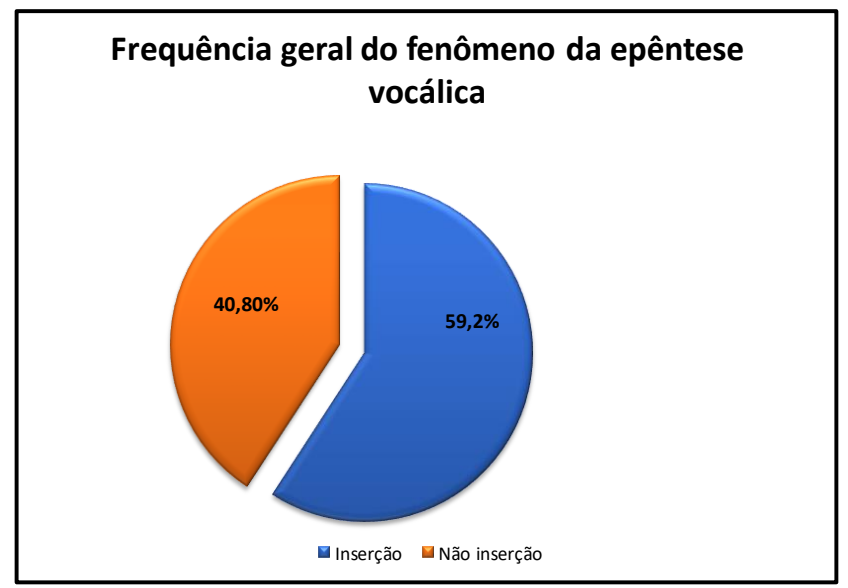

Gráfico 01: Frequência geral do fenômeno da epêntese vocálica.

Diante de tal fenômeno e principalmente ao levar em consideração que o fator sonoridade do segundo elemento do cluster foi selecionado pelo programa como o mais relevante, nos dados desta pesquisa, pode-se entender que, no processo de ensino de inglês como L2, pode ser que dar uma maior atenção aos vocábulos que contenham os clusters /sn/, /sl/ ou /sm/ seja importante para uma melhor aprendizagem por alunos brasileiros aprendizes de inglês como L2.

Além disso, as três consoantes presentes nesses clusters são homorgânicas, isto é, apresentam o traço da coronalidade, ou seja, são "produzidas com o levantamento da lâmina ou ponta da língua acima da posição neutra" (SILVA, 2011, p. 83). Assim, pode ser que o traço de coronalidade presente nessas consoantes sejam responsáveis junto com a sonoridade pelo favorecimento da epêntese vocálica inicial. Dessa forma, quanto ao contexto de sonoridade do 
cluster, elementos mais sonoros como as consoantes nasais e as líquidas foram mais propícias a favorecerem o aparecimento da epêntese vocálica inicial antes de cluster $\mathrm{sC}$ do que o contexto das consoantes obstruintes que são menos sonoras.

Em relação ao contexto fonológico precedente, os dados revelaram que os contextos vocálicos são mais propensos à ocorrência da epêntese vocálica em encontro consonantal $\mathrm{sC}$ com peso relativo de 0.67 para vogal posterior e 0.51 para vogal anterior. Dessa forma, o fenômeno que contribuiu para uma porcentagem alta com contexto fonológico precedente de vogal anterior e posterior pode ter sido um processo de ressilabificação por juntura ${ }^{5}$ e não por epêntese vocálica.

Os dados mostraram ainda que os informantes de nível avançado foram aqueles que menos usaram a estratégia de inserção da vogal epentética com peso relativo de 0.34 , seguido do nível intermediário com 0.52 e por fim, o nível básico, com o maior índice de inserção da vogal epentética, com 0.63 de peso relativo.

E por fim, a respeito da consciência fonológica do falante revelou que os informantes com consciência fonológica usaram mais a epêntese vocálica inicial em encontros consonantais sC, com peso relativo de 0.55 , do que os informantes sem consciência fonológica, que tiveram peso relativo de 0.44 .

Os dados obtidos a partir da análise estatística dessa variável são curiosos, pois esperava-se que informantes com consciência fonológica não fossem propensos a utilizar a epêntese vocálica, ao contrário dos informantes sem consciência fonológica. O que os dados desta pesquisa mostram, no entanto, é que os informantes sem consciência fonológica foram menos propensos a utilizar a vogal epentética numa ressilabação do que aqueles que já tiveram a oportunidade de receber instrução formal a respeito de fonética e fonologia de língua inglesa.

Pode-se deduzir que os dados são bem próximos da margem de 0.50 , o que pode ser um indício da pouca quantidade de informantes utilizados nesta pesquisa. Além disso, outro fator que pode ter contribuído para esse resultado é que o critério para definir se o informante tinha consciência fonológica ou não foi o fato de o informante ser aluno do curso de Licenciatura em Letras com habilitação em língua inglesa, como mencionado anteriormente, e ter cursado a disciplina fonética e fonologia.

\section{CONCLUSÃO}

Ao observar os dados analisados, percebeu-se que talvez seja necessário um trabalho mais intenso por parte dos professores de L2 com os aprendizes brasileiros de inglês como L2, levando em consideração aspectos como a sonoridade do elemento trabalhado em sala de aula ou o contexto linguístico no qual esses aprendizes se inserem como forma de dar ênfase a determinados aspectos para que os aprendizes de inglês como L2 possam adquirir, de forma mais sólida, a língua alvo.

Os resultados alcançados contribuem não só para entender como ocorre a aprendizagem de inglês como L2 por aprendizes brasileiros, mas promove também implicações pedagógicas no ensino de inglês como L2. Conhecer as nuances que fazem parte do sistema linguístico, tanto o materno quando o dito estrangeiro, é importante para um melhor aprendizado da língua alvo, levando em consideração que, no processo de aprendizagem de uma L2 se dá de forma consciente.

Um professor de inglês como L2 que tem conhecimento dessas peculiaridades de aprendizagem de línguas será capaz de compreender, por exemplo, que, em níveis mais básicos

\footnotetext{
5 A juntura é definida por Silva (2011, p. 138) como um "contexto de transição entre domínios. Pode envolver sílabas, pés métricos, morfemas, palavras ou sentenças". Dentre os processos de juntura há a degeminação, quando dois sons passam a soar como um único som; a elisão, que envolve a queda de consoantes, vogais ou sílabas; e o sândi, quando ocorre o agregamento de formas imediatas.
} 
de proficiência, o aprendente pode utilizar-se da epêntese vocálica como um suporte da língua materna para a aprendizagem da língua alvo e que, nesse período, o trabalho para que não haja uma fossilização dessa forma de produção é importante, ao mesmo tempo, em que se compreende tratar-se de um período que não é permanente.

De maneira intrínseca, ao ser importante para o professor de L2 ter conhecimento dessas características das línguas maternas e alvo, bem como do aprendizado de L2, para o aprendente também é importante conhecer alguns aspectos, certas nuances da L2 em aprendizagem também para que, ao se tornar consciente dos aspectos de pronúncia e das demais questões da língua algo, esse aprendente possa desenvolver as suas próprias estratégias de aprendizagem da língua alvo. Parece-nos que quando os indivíduos envolvidos no processo de ensino/aprendizagem de uma L2 tomam conhecimento sobre aspectos da língua, seja eles, estruturais, situacionais, de produção, isso pode levar a favorecer também a adequação de pronúncias que estavam estabilizadas na produção desses aprendizes e em caminhos de fossilização.

\section{REFERÊNCIAS}

ABRAHAMSSON, N. 1999. Vowel Epenthesis of /sC(C)/ Onsets in Spanish/Swedish Interphonology: A Longitudinal Case Study. Language learning, v. 49, n.3, set., p. 473-508.

BETTONI-TECHIO, M.; KOERICH, R. D. 2007. Perceptual training on the pronunciation of /s/-clusters in Brazilian Portuguese/English interphonology. New Sounds 2007: Proceedings of the Fifth International Symposium on the Acquisition of Second Language Speech.

BOUDAOUD, M.; CARDOSO, W. 2009. Vocalic [e] epenthesis and variation in Farsi-English interlanguage speech. Concordia Working Papers in Applied Linguistics, 2.

CARDOSO, W. 2004. The variable acquisition of English word-final stops by Brazilian Portguese speakers. Proceedings of the 7th Generative Approach to Second Language Acquisition Conference (GASLA, 2004) Somerville, MA. Cascadilla Proceedings Project.

W. 2007. The variable development of English word-final stops by Brazilian Portuguese speakers: A stochastic optimality theoretic account. Language variation and change, v.19, p. 1-30.

W. 2008. The Development of sC Onset Clusters in interlanguage: markedness vs. frequency effects. Proceedings of the 9th Generative Approaches to Second Language Acquisition Conference (GASLA 2007), ed. Roumyana Slabakova et al., 15-29. Somerville, MA: Cascadilla Proceedings Project.

W. 2008. Word-final stops in Brazilian Portuguese English: acquisition and pronunciation instruction. Ilha do desterro, Florianópolis n. 55, p. 153-172 jul./dez.

, W., JOHN, P.; FRENCH, L. 2009. The variable perception of /s/ + coronal onset clusters in Brazilian Portuguese English. In: WATKINS, M. A.; RAUBER, A.; BAPTISTA, B. O. (Orgs.) 2009. Recent research in second language phonetics/ phonology: Perception and production. Newcastle upon Tyne: Cambridge Scholar, p. 174-202.

CARLISLE, R. 1988. The effects of markedness on epenthesis in Spanish/English interlanguage phonology. Issues and Developments in English and Applied Linguistics, 3, 15-23.

R.S. 1991. The Influence of Environment on Vowel Epenthesis in Spanish/English Interphonology. Applied linguistics, v.12, n.1, p. 76-95.

, R. 1992. Environment and markedness as interacting constraints on vowel epenthesis.

In: J. Leather; JAMES, A (Eds.), New sounds 92 (p. 64-75). Amsterdam: University of Amsterdam Press.

R. S. 1994. Markedness and environment as internal constraints in the variability of interlanguage phonology. In: M. Yavas (ed.) First and Second Language Phonology. San Diego: Singular Publishing Company. p. 223-249.

R. 1997. The modification of onsets in a markedness relationship: Testing the interlanguage structural conformity hypothesis. Language learning, v.47, p. 327-361. 
R. 1998. The acquisition of onsets in a markedness relationship. A longitudinal study. Studies in second language acquisition. 20, 245-260. (Special issue: Interlanguage Phonetics and Phonology; edited by R. C. Major).

CARLISLE, R. S.; ESPINOSA, J. A. C. 2010. The Production of /.sC/ Onsets in a Markedness Relationship: A Longitudinal Study. In K. Dziubalska-Kołaczyk, M. Wrembel,; KUL M. (Eds.), Proceedings of the 6th international symposium on the acquisition of second language speech, New Sounds 2010, Poznań, Poland, Poznan: Adam Mickiewicz University.

CHEN, S. 2003. Acquisition of English onset clusters by Chinese learners in Taiwan. The University of Edinburgh, Postgraduate Conference Proceedings, 2003. Disponível em: http://www.ling.ed.ac.uk/ pgc/archive/2003/proc03/Szu-wei_Chen03.pdf.

COLLISCHONN, G. 1996. Um estudo da epêntese à luz da teoria da sílaba de Junko Ito (1986). Letras de hoje, Porto Alegre, v. 31, n.2, p. 149-158.

G. 2010. A sílaba em português. In .: BISOL, Leda (org.). Introdução a estudos de fonologia do português brasileiro. Porto Alegre: Editora da PUC-RS, $5^{\mathrm{a}}$ ed.

CORNELIAN JR, D. 2007. Brazilian learners' production of initial /s/ clusters: Phonological structure and environment. New Sounds 2007: Proceedings of the Fifth International Symposium on the Acquisition of Second Language Speech.

DUBOIS, J. et al. (1978) 2006. Dicionário de lingüistica. São Paulo: Cultrix.

ESCARTÍN, C. I. 2005. The development of $s C$ onset clusters in Spanish English. Tese - Concordia University, Canadá.

GASS, S.; SELINKER, L. (eds) 2008. Language transfer in language vs learning. Newbury House, Rowley, Massachusetts.

LABOV, W. 2008. Padrões sociolinguísticos. Tradução de Marcos Bagno; $\mathrm{M}^{a}$ Marta Pereira Scherre e Caroline Rodrigues Cardoso. São Paulo: Parábola Editorial.

LONG, M. H. Stabilization and fossilization in interlanguage development. In: DOUGHTY, K.; LONG, M (Ed): The Handbook of Second Language Acquisition. (p. 487-535). Malden, MA: Blackwell, 2005.

MILDNER, V.; TOMIC, D. 2011. Developmental aspects of initial sC clusters in Croatian children. Proceedings of the $17^{\circ}$ International Congress of Phonetic Sciences. Hong Kong City, University of Hong Kong, p. 1382-1386.

PEREYRON, L. 2008. Epêntese vocálica em encontros consonantais mediais por falantes porto-alegrenses de inglês como lingua estrangeira. Dissertação (Mestrado) - Pontifícia Universidade Católica do Rio Grande do Sul, Porto Alegre.

RAUBER, A. S. 2002. The production of English initial /s/ clusters by Portuguese and Spanish EFL speakers. Unpublished Master's thesis, Universidade Federal de Santa Catarina, Florianópolis, SC, Brazil.

RAUBER S.; BAPTISTA 2004. The production of English initial /s/ clusters by Portuguese and Spanish EFL speakers. Rev. Est. Ling., Belo Horizonte, v. 12, n. 2, p. 459-473.

REBELLO, J. T. 1997. The acquisition of English initial /s/ clusters by Brazilian EFL learners. Florianópolis: UFSC.

SANKOFF, D.; TAGLIAMONTE, S.; SMITH, E. 2005. GoldV arb X: a variable rule application for Macintosh and Windows. Department of Linguistics. University of Toronto.

SILVA 2011. Dicionário de fonética e fonologia. Contexto.

Submetido em 30/11/2018

Aceito em 11/04/2019

Publicado em 02/08/2019 